ROCZNIKI HUMANISTYCZNE

Tom LXVII, zeszyt $10-2019$

DOI: http://dx.doi.org/10.18290/rh.2019.67.10-2

KATARZYNA BUCZEK

\title{
КАМИШИБАЙ-ТЕАТР КАК СРЕДСТВО, УПОТРЕБЛЯЕМОЕ В ПРОЦЕССЕ ОБУЧЕНИЯ ИНОСТРАННОМУ ЯЗЫКУ В ГРУППАХ ДЕТЕЙ ДОШКОЛЬНОГО И МЛАДШЕГО ШКОЛЬНОГО ВОЗРАСТА
}

Учиться - никогда не поздно - эти слова находят свое подтверждение и в условиях обучения иностранным языкам. Нужно все-таки заметить, что ребенок овладевает языком бессознательно, успешно и прочно, так как мы родимся с умением быстро и без усилий овладеть любым языком. Психологи называют даже «критический возраст», до которого следует начинать усваивать язык. Мнения экспертов неоднозначны, одни определяют эту границу как 5, другие даже как 15 лет. Существует также мнение, что в искусственных условиях, значит вне языковой среды, лучшие результаты обучения языку достигают взрослые учащиеся (J.B. Caroll, E. Throndike, S. Krashen, T. Trell) ${ }^{1}$.

На результат в овладении иностранным языком влияют многочисленные факторы. Среди них можно выделить те, которые способствуют усвоению языка, но также такие, которые препятствуют. Лишь тогда, когда мы их узнаем, будем в состоянии предупредить их негативное влияние и использовать их потенциал.

Во-первых, стоит назвать память, которая выполняет неоценимую роль в процессе обучения, в том числе, в условиях усвоения иностранного языка. Принято считать, что у детей память лучше, но целесообразно обратить внимание на специфику памяти у детей и у взрослых. Итак, дети

Dr KATARZYNa BuczeK - adiunkt, Instytut Filologii Rosyjskiej Uniwersytetu Rzeszowskiego; e-mail: k_t@@poczta.onet.eu

${ }^{1}$ Больше на эту тему см. K. BUCzeк, Etap początkowy w nauczaniu języka rosyjskiego studentów rozpoczynających akwizycje języka od podstaw, Rzeszów: Wydawnictwo Uniwersytetu Rzeszowskiego 2014, c. 32-43. 
действительно запоминают новую информацию быстрее, чем взрослые, но в связи с небольшим объемом памяти они не в состоянии удержать в памяти длинные высказывания и так же быстро как запомнили, забывают новый материал. Кроме того, у детей не развита еще логическая память, связанная с мышлением.

Следующим фактором, которому стоит уделить внимание, является физиологический аспект. Как утверждают физиологи, есть препятствия биологической натуры, которые не позволяют взрослым овладеть фонетической стороной языка, в такой степени, как в случае тех, которые знакомились с языком в детстве. Все благодаря хорошему фонематическому слуху и большой пластичности речевого аппарата у детей ${ }^{2}$.

Благодаря относительно небольшому количеству образцов речи в родном языке, дети в состоянии кодировать мысли новым способом. Им характерно отсутствие, свойственного взрослым, схематизма мышления.

Не менее важные для процесса работы над иностранным языком, психологические аспекты. Дети, заинтересованные всем новым, у них наблюдается небольшой самокритицизм, отсутствие барьеров и свойственного взрослым страха перед осрамлением.

Дети любопытные, спонтанные, самоуверенные, готовые рисковать. Охотно принимают участие в новых активностях, легко приспосабливаются к новым условиям, проявляют большой интерес к окружающему. Но они также чувствительные, доверчивые, и характеризуются большой эмоциональностью.

К сожалению, не всегда юный возраст оказывает положительное влияние на процесс усвоения иностранного языка. Среди факторов, которые могут осложнять этот процесс целесообразно назвать отсутствие или низкую мотивировку к изучению языка. Для детей, которые усваивают язык в натуральных условиях, усвоение языка является необходимостью. В свою очередь, у детей, учащих язык в искусственных условиях, низкая мотивировка или даже ее отсутствие.

У детей, особенно младших, ограниченная возможность сосредоточить внимание, они в состоянии сосредоточиться лишь на короткий срок. В этой возрастной группе наблюдаются также затруднения в самостоятельной работе, детям не хватает опыта в том, как учиться и вообще у них небольшой жизненный опыт.

В настоящее время обучение иностранным языкам на самом раннем этапе образования стало приоритетом в европейских странах. В школьном

\footnotetext{
${ }^{2}$ Там же.
} 
языковом образовании во многих странах мира, в том числе и в Польше, внедряется программа, раннего языкового образования. Начиная с первого сентября 2015 года, все дети в возрасте 5-ти лет в Польше обучаются в детских садах иностранному языку, а с 2017 года эта программа в Польше охватывает уже трехлетних малышей ${ }^{3}$. В начальной школе в плане общего образования можно выделить два этапа обучения иностранным языкам. На первом этапе, который охватывает учеников первого, второго и третьего классов начальной школы, школьники учатся одному иностранному современному языку. Начиная с четвертого класса по восьмой класс начальной школы, школьники изучают уже два иностранных языка ${ }^{4}$.

Таким образом Польша наряду с Испанией и Бельгией является одной из трех европейских стран, в которых обучение иностранному языку вводится так рано. Похожие решения вводятся с целью способствовать лучшему использованию потенциала маленьких учащихся.

По утверждению многих исследователей

младший школьный возраст является наиболее благоприятным периодом для овладения иноязычной речевой деятельностью по причине интенсивного формирования познавательных процессов, быстрого и легкого запоминания языковой информации, особой чувствительности к явлениям языка 5 .

Многие ученые отмечали положительное влияние изучаемого иностранного языка на развитие родной речи и на общее психическое развитие ребенка младшего школьного возраста (К.Д. Ушинский, ЈТ.В. Щерба, А.А. Леонтьев и др.) ${ }^{6}$.

Важно подчеркнуть, что цель обучения иностранному языку на самом раннем этапе обучения значительно отличается от целей обучения на более поздних этапах.

На этом этапе обучения язык не является самоцелью. Цель языковых упражнений - разбудить у учеников заинтересованность, показать разные способы передачи информации с помощью иностранного языка и самое

\footnotetext{
${ }^{3}$ M. Pamula-Behrens, Wszystko zaczyna się w przedszkolu - nauka języka obcego dla dzieci, „Języki Obce w szkole” 2015, nr 1, c. 8-13.

${ }^{4}$ Wczesnoszkolne nauczanie języków obcych. Zarys teorii i praktyki, red. D. Sikora-Banasik, Warszawa: Centralny Ośrodek Doskonalenia Nauczycieli 2009, s. 5-6.

${ }^{5}$ Н.В. КондРАшовА, „Становление и развитие дошкольного образования в Мордовском крае" http://www.dslib.net/obw-pedagogika/stanovlenie-i-razvitie-doshkolnogo-obrazovanija-v-mordovskom-krae.html (доступ: 26.02.2019).

${ }^{6}$ Там же.
} 
главное, обеспечить учащимся возможность привыкнуть к языку, ознакомить с его другим, отличительным звучанием и произношением. На этом этапе важна также воспитательная цель обучения, ученики получают знания о другой культуре, формируется открытость и уважение к разнообразию культур и национальностей. Неоценима роль раннего этапа обучения в формировании у учеников веры в свои способности ${ }^{7}$. В связи с тем, что цель обучения иностранному языку по отношению к маленьким детям, отличается от целей обучения на более продвинутых этапах, в старших возрастных группах, и сам процесс работы над языком должен отличаться.

Учащиеся на первых стадиях обучения должны получить достаточное количество знаний, которые идут в пассив. Затем в процессе обучения наступает период, когда они должны реагировать на услышанное или прочитанное, но реагировать только действием. И только потом, когда учащиеся накопили довольно много информации, они готовы к тому, чтобы начать говорить ${ }^{8}$.

Урок иностранного языка не только не должен, но и не может быть скучным. Удовольствие и удача в обучении иностранному языку неразрывны, веселье совпадает с натурой человека, разгоняет монотонность, противодействует скуке. Людические техники выполняют очень важную роль в обучении иностранному языку в дошкольном и младшем школьном возрасте ${ }^{9}$. По отношению к младшим детям, игра и развлекательные техники составляют базис, а иногда единственную форму обучения языку.

Хорошим приемом на занятиях по иностранному языку, на всех этапах обучения, является употребление самых разнообразных театральных техник. В настоящей статье попытаемся представить специфику и возможности использования Камишибай-театра в качестве средства обучения иностранному языку. Цель настоящей статьи - приблизить Камишибай театр как средство обучения и развития аудирования у детей в младшем школьном возрасте, а также обратить внимание на мотивирующие, развлекательные и воспитательные качества этой технологии. Для целей работы был произведен спектакль Камишибай театра «Петушок - Золотой Гребешок», который

\footnotetext{
${ }^{7}$ Postanowienie Ministra Edukacji Narodowej z dnia 14.02.2017, Dziennik Ustaw Rzeczypospolitej Polskiej, Warszawa, 24.02.2017, poz. 356.

${ }^{8}$ В.Г. КудРЕшОВА, „Техника 'storytelling' при обучении английскому языку детей в классах коррекции”, http://xn--ilabbnckbmcl9fb.xn--plai/\%D1\%81\%D1\%82\%D0\%B0\%D1\% 82\%D1\%8C\%D0\%B8/630637/ (доступ: 4.09.2019).

${ }^{9}$ M. ŻEBrowska, Psychologia rozwojowa dzieci i młodzieży, Warszawa: PWN 1966.
} 
состоялся 01.03.2019 года в группе детей - учеников подготовительного класса детского сада номер 23 города Жешува ${ }^{10}$.

紙 (ками - бумага) 芝居 (шибай - игра, драма). Камишибай - это форма визуального и совместного повествования, которая соединяет в себе использование нарисованных вручную изображений и живое повествование презентующего ${ }^{11}$.

Корни Камишибай уходят в различные традиции визуального повествования, которые были распространены в прошлом в Японии. Этот вид искусства появился в Японии в XII веке. Буддистские монахи-странники ходили по стране и распространяли свои учения с помощью бумажных свитков с рисунками. Современная форма этого театра появилась только в начале XX века, а в 30-е и 40-е гг. прошлого века завоевала большую популярность. Продавцы сладостей ездили по деревням на велосипедах с деревянными рамками, на которых они меняли картинки, рассказывая разные занимательные истории с целью привлечь внимание. До начала 50-х годов Камишибай был любимым средством развлечения, но потом в связи с распространением телевизоров, традиция театра постепенно исчезала ${ }^{12}$. В настоящее время Камишибай широко используется не только в Японии, но также в европейских странах в разных образовательных заведениях, детских садах, школах, библиотеках.

Технически Камишибай-театр несложная технология, не требует больших затрат времени, денег, не требует от рассказчика специальных умений. Поставить спектакль Камишибай можно в любых условиях. Для Камишибай-театра употребляется деревянный ящик с открывающимися дверками, как экран марионеточных театров, который, как правило, ставится на стол. В ящике нет задней стенки, в это место ставятся картинки. Картинок для спектакля обычно более десятка, чаще всего они формата А3, они изображают сценки к тексту, который представляется рассказчиком. На иллюстрациях должно быть минимум деталей, чтобы не мешать и не отвлекать внимания от самого важного. Иллюстрации ставятся последовательно, в соответствии с текстом, таким образом, чтобы по мере чтения/рассказа можно было их

\footnotetext{
${ }^{10} \mathrm{http} / /$ pp23.rzeszow.pl/aktualnosci/wydarzenia/1380-1-03-2019-tatr-kamishibai-spotkanie-z-mama-mikolaja-w-grupie-smerfow.html (доступ: 10.03.2019).

11 „Камишибай: уроки визуального повествования из Японии”, http://presportal.ru/ prezentaciya/kamishibaj-uroki-vizualnogo-povestvovaniya-iz-yaponii/ (доступ: 26.02.2019).

12 Т.В. МихеввА, Театральная технология «Камишибай» как средство развития творческой активности обучающихся в прочессе обучения иностранному языку, КировоЧепецк 2016, с. 3.
} 
легко менять. Это позволяет демонстрировать иллюстрации одновременно с представлением текста. Иногда с задней стороны картинки находится текст для чтения или его фрагменты - подсказки рассказчику. Но надо подчеркнуть, что самые хорошие мастера Камишибай ведут рассказ без текстовой опоры, что дает им возможность лучшего контакта с публикой и дает возможность почувствовать атмосферу театра. Текст для Камишибай-театра в группах детей должен быть хорошо подобран, в нем не может быть ничего лишнего, если есть такая необходимость, можно сократить ход событий. Важно, чтобы текст отвечал сложностью возможностям учащихся. Хорошо, чтобы текст был визуализирован, инсценирован и понятен по контексту. Историю надо рассказывать выразительно и медленно, а рассказ должен сопровождаться мимикой, жестом, рассказчик может делать паузы, изменять темп речи, менять голос в зависимости от героя, в которого воплощается ${ }^{13}$.

В работе над развитием аудирования с употреблением театра Камишибай можно выделить три этапа:

- предтекстовой этап,

- текстовый этап,

- послетекстовый этап.

Первый предтекстовой этап - это все приемы, которые проводятся до подачи текста. Цель этого этапа работы заключается в том, чтобы разбудить интерес и подготовить учащихся к восприятию текста. Предпринимаемые действия помогают сосредоточить внимание, должны вызвать у детей желание выслушать историю. На этом этапе работы дети имеют возможность ознакомиться с атмосферой истории, с ключевыми словами, без которых понимание текста осложняется. Чтобы увеличить интерес, можно пригласить героя рассказа в аудиторию. Это может быть марионетка, но также учитель может воплотиться в его роль, подчеркнуть характер героя каким-то предметом, одеждой. Хорошим приемом является также раздача реквизитов, которые появляются в истории. На дальнейших этапах работы дети будут их активно использовать, но теперь они подсказывают им, о чем идет речь в истории и пробуждают интерес к этому, что состоится. Прежде чем представить текст, можно показать детям иллюстрацию, касающуюся данной истории и попросить их угадать, с чем она связана. Придумывать свои варианты, идеи и прогнозы дети могут на основании реквизитов, введенных слов, героев, которые к ним пришли или на основании заглавия текста.

\footnotetext{
${ }^{13}$ Там же.
} 
После такой подготовки переходим к следующему текстовому этапу - работы во время подачи текста. Прежде чем начнется спектакль все должны занять свои места и ожидать начала спектакля. Начало спектакля, как правило, возвещает звук деревянных трещоток hyoshigi 拍子木. Это два деревянных кубика ударяемых друг о друга, но можно их заменить любым звучащим предметом: колокольчиком, каким-то инструментом, или даже чашкой, о которою будем ударять ложечкой. Магический звук переносит нас в театр, открываются дверки ящика и перед зрителями появляется настоящая сцена. Благодаря такой конструкции ящика организуется пространство таким образом, что лишние детали не отвлекают внимания зрителей и оно направлено на иллюстрацию и восприятие текста.

Камишибай театр отличается от других видов театра тем, что зрители принимают в нем активное участие. Участие в спектакле театра Камишибай не заключается только в том, чтобы посмотреть и выслушать историю. Перед учащимися ставятся разнообразные задания, которые способствуют лучшему восприятию, пониманию и запоминанию материала.

Во время подачи текста рассказчик/учитель вовлекает учеников в деятельность. Ученики повторяют слова, хором или отдельно, поднимают реквизиты, марионетки или листки бумаги с рисунками или написанными словами. Могут подражать звуками или движением какого-то героя рассказа, отвечают на вопросы, ставящиеся учителем и сами задают вопросы либо рассказчику, либо героям. В ходе спектакля вместо иллюстрации учитель может показать ученикам картинку с вопросительным знаком, учащиеся должны тогда придумать, что могло случиться, как должен реагировать герой в данной ситуации, можно попросить учащихся описать внешность героя и т.п. Учитель может представить историю без окончания и попросить детей придумать, что произошло дальше. Дети могут работать в группах или самостоятельно, они не только придумывают окончание истории, но также должны подготовить рисунок, иллюстрирующий представленные события. В следующую очередь представляются все придуманные детьми заключения и, затем, они сравниваются с оригинальным заключением, которое учитель приводит после выступления всех групп. Это упражнение можно еще включить во второй этап работы, во время подачи текста, но оно является также плавным переходом в третий, последний этап работы, послетекстовый - после просмотра спектакля. Цель этого этапа работы заключается в том, чтобы закрепить новый материал. Работа проводится в самых разнообразных формах. Если вначале учитель не назвал заглавия произведения, на этом этапе можно попросить детей озаглавить историю. Дети дают свои варианты, которые сравниваем с оригинальным заглавием. 
Можно попросить детей уложить иллюстрации последовательно, подобрать слова к иллюстрациям, можно приготовить лишние иллюстрации или такие, на которых чего-то не хватает, а дети должны их исправить. Учитель может также прочитать фрагмент высказывания героя, а ученики должны угадать, чьи это слова. На основании спектакля можно попросить детей воплотиться в выбранного героя или коллективно сыграть сценку. Дети могут также использовать пантомиму для передачи чувств и состояния героев. На более продвинутом этапе ученики могут подготовить спектакль, воплощаясь в роли героев, или самостоятельно подготовить историю для Камишибай театра.

Возможности упражнений практически не ограничены.

Технология Камишибай вписывается в популярный в настоящее время метод обучения иностранным языкам - сторителлинг (storytelling) ${ }^{14}$ - pacсказывание историй. Метод основан на вечной силе рассказов, ведь рассказывание самых разнообразных историй естественно для человека, это основа любой коммуникации. Наши предки сначала употребляли устную форму коммуникации, лишь потом появилось письмо. Рассказ - это также самый популярный, самый хороший, самый интуитивный и универсальный метод обучения детей родному языку, который успешно можно и стоит перенести на условия обучения иностранным языкам.

Представляемые с помощью театра Камишибай истории помогают детям выучить слова, фразы, произношение и грамматические конструкции. Словарный запас обогащается, так как слушая историю, дети сталкиваются с большим количеством слов, кроме того, в историях ключевые слова часто повторяются, что способствует их лучшему запоминанию. Не менее важен также факт, что слова не появляются отдельно, а в контексте.

Употребление технологии Камишибай способствует совершенствованию умения слушать с пониманием и увеличивает языковую осведомленность учащихся.

Аудирование - это процесс восприятия звучащей речи помимо слушания предполагающий еще слышание, понимание и интерпретацию воспринимаемой на слух информации ${ }^{15}$.

Н.В. Елухина выделяет следующие шесть умений, как основные умения аудировать:

- отделять главное от второстепенного;

${ }^{14}$ Метод был изобретен и успешно опробован Дэвидом Армстронгом.

${ }^{15}$ В.М. ФилАтов, Методика обучения иностранным языкам в начальной и основной общеобразовательной школе, Ростов на Дону: Феникс 2004, с. 238. 
- определять тему сообщения;

- членить текст на смысловые куски;

- устанавливать логические связи;

- выделять главную мысль;

- воспринимать сообщения в определенном темпе, определенной длительности, до конца без пропусков ${ }^{16}$.

С помощью технологии Камишибай ученики учатся интерпретации текста. Благодаря тому, что текст разделяется на фрагменты, он не слишком длинный для возможностей воспринимать на слух самыми младшими учениками. Таким образом дети учатся членить текст на смысловые куски с одной стороны, с другой, устанавливать логические связи. Хорошо подобранные упражнения помогают ученикам выделить главную мысль в тексте. Кроме того, расширяется кругозор учащихся, они знакомятся с различными культурными, географическими, историческими и социальными аспектами. С помощью представляемых историй учитель передает ученикам разнообразные ценности. Благодаря технологии Камишибай развивается воображение учащихся, они становятся более внимательными, наблюдательными, учатся сосредоточивать и удерживать внимание. Кроме того, истории в театре Камишибай являются хорошим стимулом для говорения, вызывают у учеников желание высказаться.

В своей гипотезе об усвоении языка Крашен ${ }^{17}$ утверждает, что эмоциональное состояние сильно влияет на дидактический процесс. Он утверждает, что, если человек расслаблен, в хорошем настроении, счастлив, то он легче и лучше учится.

Использование театрализованных упражнений, в том числе Камишибай-театра, способствует сильному, эмоциональному побуждению, благодаря чему увеличивается познавательная заинтересованность. Неоценимая роль театра, в том числе Камишибай, в развитии эмоциональной сферы и творческих способностей учащихся. Такая форма занятий помогает также преодолеть языковой барьер, поддерживает интерес к предмету и пробуждает мотивацию, а обучение проходит в развлекательной, приятной форме.

Хорош этот метод тем, что учащиеся в процессе обучения ощущают себя очень комфортно. Необходимый эффект достигается за счет того, что всю получаемую информацию человек пропускает через себя. Немаловажно также то, что

\footnotetext{
${ }^{16}$ В.М. ФилАтов, Методика, с. 248.

${ }^{17}$ Американский психолингвист Стивен Крашен (1970-1980-е гг.).
} 
в процессе изучения языка по данному методу учащиеся общаются не только с преподавателем, но и друг с другом ${ }^{18}$.

В эпоху вездесущей электроники Камишибай - отличный трамплин. Конечно, иллюстрации к рассказываемым историям можно показать на слайдах на проекторе, что значительно облегчает работу учителя, а Камишибай всегда требует своего рода игры и открытости по отношению к зрителям / слушателям, но благодаря тому, у нас есть прямой зрительный контакт с аудиторией. В Камишибай театре история является самой важной, и именно она создает связь со слушателями. Благодаря уникальной форме Камишибай театра появляется неповторимая магия театра, которой электронные технологии не в состоянии создать и, таким образом, можно показать детям, что не только с компьютером и планшетом можно интересно провести время.

\section{БИБЛИОГРАФИЯ}

BuczeK K., Etap początkowy w nauczaniu języka rosyjskiego studentów rozpoczynajacych akwizycje języka od podstaw, Rzeszów: Wydawnictwo Uniwersytetu Rzeszowskiego 2014.

Pamula-Behrens M., Wszystko zaczyna się w przedszkolu - nauka języka obcego dla dzieci, „Języki Obce w szkole” 2015, nr 1, c. 8-13.

Wczesnoszkolne nauczanie języków obcych. Zarys teorii i praktyki, red. D. Sikora-Banasik, Warszawa: Centralny Ośrodek Doskonalenia Nauczycieli 2009.

Żebrowska M., Psychologia rozwojowa dzieci i młodzieży, Warszawa: PWN 1966.

КондРАшова Н.В., „Становление и развитие дошкольного образования в Мордовском крае” [Kondrashova N.V., „Stanovleniye i razvitiye doshkol'nogo obrazovaniya v Mordovskom kraye"], http://www.dslib.net/obw-pedagogika /stanovlenie-i-razvitie-doshkolnogo-obrazovanija-v-mordovskom-krae.html (доступ: 26.02.2019).

Кудрешова В.Г., „Техника storytelling при обучении английскому языку детей в классах коррекции” [Kudreshova V.G., „Tekhnika storytelling pri obuchenii angliyskomu yazyku detey v klassakh korrektsii"], http://xn-ilabbnckbmc19fb.xn--plai/\%D1\%81\%D1\%82\%D0\% B0\%D1\%82\%D1\%8C\%D0\%B8/630637/ (доступ: 4.09.2019).

Михевва Т.В., Театральная технология «Камишибай»как средство развития творческой активности обучающихся в процессе обучения иностранному языку, Кирово-Чепецк 2016 [Mikheyeva T.V., Teatral'naya tekhnologiya «Kamishibay» kak sredstvo razvitiya tvorcheskoy aktivnosti obuchayushchikhsya v protsesse obucheniya inostrannomuyazyku, Kirovo-Chepetsk 2016].

Филатов В.М., Методика обучения иностранным языкам в начальной и основной общеобразовательной школе, Ростов на Дону: Феникс 2004 [Filatov V.M., Metodika obucheniya inostrannym yazykam v nachal'noy i osnovnoy obshcheob-razovatel'noy shkole, Rostov na Donu: Feniks 2004].

18 „Техника storytelling” (доступ: 4.09.2019). 


\section{TEATR KAMISHIBAI JAKO NARZĘDZIE WYKORZYSTYWANE W PROCESIE NAUCZANIA JĘZYKA OBCEGO W GRUPACH DZIECI W WIEKU PRZEDSZKOLNYM I WCZESNOSZKOLNYM}

\section{Streszczenie}

$\mathrm{Na}$ rezultat $\mathrm{w}$ procesie pracy z językiem obcym wpływają różnorodne czynniki, zarówno takie, które sprzyjają opanowaniu języka obcego, jak i te, które będą ten proces utrudniać. W niniejszym artykule zwrócono uwagę na różnorodne aspekty natury psychologicznej i fizjologicznej, które w znaczący sposób wpływają na opanowanie języka obcego przez małe dziecko. Biorąc pod uwagę specyfikę pracy z dziećmi, zaproponowano teatr Kamishibai, jako technikę, która sprawdza się w pracy z dziećmi w wieku przedszkolnym i wczesnoszkolnym.

Słowa kluczowe: teatr; Kamishibai; storytelling; dzieci; nauczanie języka obcego.

\section{THE KAMISHIBAI THEATRE AS THE TOOL USED IN THE PROCESS OF THE FOREIGN LANGUAGE TEACHING IN GROUPS OF PRE-SCHOOL CHILDREN AND EARLY-SCHOOL}

Su m mary

In the process of the work with foreign language there are numerous factors that affect results, one of them support mastering a foreign language, the other ones make this process difficult. In the article, the attention was directed to diverse aspects of the psychological and physiological nature, which significantly influence acquiring a foreign language by a small child. A Kamishibai theatre considered as a technique, which is working with pre-school as well as early-school children was suggested, taking the specificity of the work with children into consideration.

Key words: theatre; Kamishibai; storytelling; children; foreign language teaching. 